\title{
Role of uromodulin and complement activation in the progression of kidney disease
}

\author{
FEI SHEN $^{1 *}$, MAOJING LIU $^{1 *}$, FEI PEI $^{1}$, LI YU $^{1,2}$ and XIANGDONG YANG ${ }^{1}$ \\ ${ }^{1}$ Department of Nephrology, Qi Lu Hospital of Shandong University; ${ }^{2}$ Department of Cardiovascular Surgery, \\ Shandong Provincial Hospital Affiliated to Shandong University, Jinan, Shandong 250012, P.R. China
}

Received February 5, 2020; Accepted March 26, 2021

DOI: $10.3892 / \mathrm{ol} .2021 .13090$

\begin{abstract}
Uromodulin (UMOD) is a glycoprotein that is selectively expressed on the epithelial cells of the thick ascending limb of Henle's loop and the early distal renal tubule. The present study aimed to investigate whether UMOD was associated with complement activation in patients with renal diseases. In addition, its biological function was examined in vitro. The expression levels of UMOD and complement components, including C1q, C3, C4 and C3a, and membrane attack complex (MAC) in the plasma of patients with IgA nephropathy (IgAN; $\mathrm{n}=58$ ) and lupus nephritis ( $\mathrm{LN} ; \mathrm{n}=36$ ) were detected using ELISA, which was used to determine the association between UMOD expression and complement components. In addition, a simulated hypoxia-reoxygenation $(\mathrm{H} / \mathrm{R})$ model was used to stimulate UMOD expression in mouse inner medullary collecting duct cells. Additionally, the association between UMOD expression and complement components C1q and C3d at the cellular level was identified using western blotting and immunofluorescence, respectively. It was revealed that the plasma UMOD concentration was significantly decreased in patients with IgAN and LN compared with in healthy controls, and the levels of $\mathrm{C} 3 \mathrm{a}$ and MAC were significantly increased in the plasma of patients with $\operatorname{IgAN}$ and LN. Furthermore, the plasma levels of $\mathrm{C} 1 \mathrm{q}, \mathrm{C} 3$ and $\mathrm{C} 4$ in patients with LN, but not in patients with $\operatorname{IgAN}$, were significantly decreased compared with in healthy controls. The plasma levels of UMOD were negatively correlated with the plasma C3a and MAC concentrations. However, the plasma levels of UMOD were significantly and positively correlated with the plasma C1q concentration, but not with that of $\mathrm{C} 3$ and $\mathrm{C} 4$. It was identified that UMOD expression started to increase after $1 \mathrm{~h}$ of simulated $\mathrm{H} / \mathrm{R}$, and continued to increase at 6 and $12 \mathrm{~h}$. In
\end{abstract}

Correspondence to: Dr Xiangdong Yang, Department of Nephrology, Qi Lu Hospital of Shandong University, 107 Cultural West Road, Jinan, Shandong 250012, P.R. China

E-mail: yangxiangdong24@163.com

*Contributed equally

Key words: uromodulin, complement components, IgA nephropathy, lupus nephritis addition, cells with lower UMOD expression had higher C3d expression in vitro. Collectively, the present results suggested that UMOD was associated with severe complement activation and may be involved in complement-mediated immune protection by inhibiting complement activation in renal disease.

\section{Introduction}

Chronic kidney disease is ubiquitous and associated with significant morbidity and mortality, and is caused by hypertension, infection, diabetes and the excess of complement activation (1). Complement activation accelerates progressive kidney diseases by stimulating the synthesis and release of pro-inflammatory cytokines, including $\mathrm{TNF} \alpha$ and interleukins, and reactive oxygen species, as well as increasing the synthesis of matrix proteins (2).

Uromodulin (UMOD) is the most abundant protein in normal human urine and is selectively expressed by epithelial cells of the thick ascending limb of Henle's loop and the early distal renal tubule $(3,4)$. Previous studies have revealed that UMOD serves an important role in patients with acute and chronic kidney diseases $(5,6)$. The levels of UMOD in urine and blood are closely associated with the estimated glomerular filtration rate (eGFR) in patients with chronic kidney disease (7-9). Our previous studies have suggested that the levels of UMOD were decreased in urine and were associated with interstitial fibrosis, tubular atrophy and low eGFR in patients with IgA nephropathy (IgAN) (10-12). Furthermore, UMOD-knockout mice exhibit more serious injury compared with wild-type mice after ischemia-reperfusion injury $(13,14)$; however, the potential underlying mechanism requires to be elucidated.

Complement is an important component of the innate immune system that consists of $>30$ types of proteins that widely exist in the circulation, tissues and cell membrane surface (15-17). Abnormal complement activation exists in a variety of kidney diseases, including lupus nephritis (LN) (18), $\operatorname{IgAN}(19)$ and membranoproliferative glomerulonephritis (20). Previous studies have reported that numerous types of kidney cells present a variety of complement components and complement receptors, such as $\mathrm{C} 2, \mathrm{C} 3, \mathrm{C} 4$, factor $\mathrm{B}$, factor $\mathrm{H}, \mathrm{CR} 1$, CR3 and C3aR (21,22). Moreover, Schiano et al (23) revealed that mice with complement factor $\mathrm{H}$ gene-knockout exhibited renal tubulointerstitial damage due to excessive complement activation. However, the exact mechanism remains unknown. 
The present study aimed to investigate the potential clinical significance of UMOD, and its association with complement activation and histopathological characteristics in patients with kidney disease.

\section{Materials and methods}

Patients and samples. The present study was approved by the Ethical Committee of Qi Lu Hospital of Shandong University (Jinan, China). Written informed consent was obtained from all patients and healthy controls involved in the study. The study population included 58 patients with IgAN composed of 38 men and 20 women with a median age of 33 years (range, 27-48 years) and 36 patients with LN composed of 7 men and 29 women with a median age of 34 years (range, 28-46 years) between January 2014 and December 2018 at Qi Lu Hospital of Shandong University. Patients were included in the study according to the following requirements: i) Age of $\geq 18$ years; and ii) biopsy-confirmed primary IgAN or LN. Additionally, 30 healthy volunteers (median age, 41 years; range, 25-61 years) were enrolled as controls, including 15 males and 15 females. Plasma samples $(0.5 \mathrm{ml})$ were collected on the day of renal biopsy and stored at $-80^{\circ} \mathrm{C}$ until assay. Clinical pathological parameters were also collected. eGFR was calculated using the Chronic Kidney Disease Epidemiology Collaboration equation (24).

UMOD, C3a, membrane attack complex (MAC), Clq, C3 and $C 4$ measurements. The plasma UMOD levels were measured using a commercial human uromodulin ELISA kit (cat. no. RD191163200R; BioVendor R\&D) according to the manufacturer's protocol as described previously (25). Based on median expression levels of plasma UMOD in the $\operatorname{IgAN}(217 \mathrm{ng} / \mathrm{ml})$ and LN (169 ng/ml) groups, patients were classified into low and high expression subgroups. The plasma concentrations of $\mathrm{C} 3 \mathrm{a}$ and MAC were determined using by ELISA (cat. no. A031 and A020, respectively; Quidel Corporation) according to the manufacturer's instructions. The plasma concentrations of $\mathrm{Clq}$, $\mathrm{C} 3$ and $\mathrm{C} 4$ were measured using immunoturbidimetric assays (Shanghai BeiJi Biochemical reagent Co., Ltd.) according to the manufacturer's instructions.

Renal biopsy. All renal perforation specimens were collected and fixed in $4 \%$ paraformaldehyde at room temperature for $24 \mathrm{~h}$. Following fixation, the samples were embedded in paraffin and cut into $4-\mu \mathrm{m}$-thick sections, which were then dewaxed in xylene $\left(80-90^{\circ} \mathrm{C}\right)$, rehydrated using a descending ethanol series (100, 85 and $75 \%$ ethanol) and washed in water. Following antigen retrieval, the spontaneous fluorescence quencher (Wuhan Servicebio Technology Co., Ltd; cat. no. G1221) was added for $5 \mathrm{~min}$ at room temperature, and the samples were rinsed with water for $10 \mathrm{~min}$. The sections were subsequently blocked using bovine serum albumin (Wuhan Servicebio Technology Co., Ltd.) for $30 \mathrm{~min}$ at room temperature and stained for $\operatorname{IgA}, \operatorname{IgG}, \operatorname{Ig} \mathrm{M}, \mathrm{C} 3$, fibrinogen and C1q for immunofluorescence analysis (data not shown). Fluorescence results were determined using a semi-quantitative scale of 0-3: 0 , No staining $(-)$; 1 , weakly positive $(+)$; 2 , positive $(++)$; and 3 , strongly positive $(+++)$. Specimens from patients with $\operatorname{IgAN}$ were evaluated according to the following Oxford classification (26): Mesangial hypercellularity $\leq 0.5$ (M0) or >0.5 (M1); segmental glomerulosclerosis absent (S0) or present (S1); endocapillary hypercellularity absent (E0) or present (E1); and tubular atrophy and interstitial fibrosis $\leq 25 \%$ (T0), 26-50\% (T1) or $>50 \%$ (T2). Specimens from patients with LN were analyzed using light microscopy according to the World Health Organization classification (27), and were then assessed for NIH activity index (AI) and chronicity index $(\mathrm{CI})$.

Cell culture and simulated hypoxia-reoxygenation $(H / R)$ ischemia model. Mouse inner medullary collecting duct (mIMCD3) cells were provided by Professor Chen Yuqing (Department of Nephrology of Peking University; Beijing, China). The cells were cultured in DMEM/F12 medium (HyClone; Cytiva) with 10\% FBS (Gibco; Thermo Fisher Scientific, Inc.) in a humidified chamber with $5 \% \mathrm{CO}_{2}$ at $37^{\circ} \mathrm{C}$. According to a previously described method (28), cells were seeded into 60-mm culture dishes. After reaching $\sim 60 \%$ confluency, the sugar-free and serum-free DMEM/F12 medium was changed and cells were cultured for $24 \mathrm{~h}$. Subsequently, an appropriate amount of sterilized mineral oil (Sigma-Aldrich; Merck KGaA; cat. no. M5310) was added to the culture dishes, cells were blocked with sterilized mineral oil for 1,6 and $12 \mathrm{~h}$ to simulate hypoxia at $37^{\circ} \mathrm{C}$. After hypoxia, the mineral oil was aspirated, the plates were washed five times with sterilized PBS, and DMEM/F12 culture medium containing $10 \%$ FBS was added. The cells were then cultured in a $5 \% \mathrm{CO}_{2}$ incubator at $37^{\circ} \mathrm{C}$ for $24 \mathrm{~h}$ for reoxygenation. Cells without any treatment were used as the control group.

Western blotting. Total proteins from $10^{6}$ cells were extracted using RIPA cell lysis buffer (Beijing Solarbio Science \& Technology Co., Ltd.) with phosphatase inhibitor and proteinase inhibitor (dilution, 100:10:1) and quantified using the Bradford method. The samples (20 $\mu \mathrm{g} / \mathrm{lane})$ were separated via $8 \%$ SDS-PAGE and transferred to PVDF membranes. The membranes were blocked with 5\% skim milk for $1 \mathrm{~h}$ at $4^{\circ} \mathrm{C}$, and then incubated with primary antibodies overnight at $4^{\circ} \mathrm{C}$, followed by incubation with horseradish peroxidase-labelled secondary antibodies (1:500; cat. no. ZF-0316; OriGene Technologies, Inc.) at room temperature for $1 \mathrm{~h}$. The primary antibodies used in the present study were as follows: Anti- $\beta$-actin (used as reference; 1:1,000; cat. no. TA-09; OriGene Technologies, Inc.), anti-UMOD (1:500; cat. no. 8595-0054; Bio-Rad Laboratories, Inc.) and anti-ClqA (1:500; cat. no. 11602-1-AP; ProteinTech Group, Inc.). The membrane was visualized using BeyoECL Plus (Shanghai Biyuntian Biotechnology Co., Ltd.), according to the manufacturer's protocol, and routine procedures using a gel imaging analyzer (Chemidoc XRS+; Bio-Rad Laboratories, Inc.). Relative signal intensity of protein expression was normalized to $\beta$-actin and quantified using ImageJ software (V1.8.0; National Institutes of Health).

Immunofluorescence assays. The cells in each group were seeded on a coverslip and cultured as aforementioned. Subsequently, cells were fixed with $4 \%$ paraformaldehyde for 30 min at room temperature, treated with $0.1 \%$ Triton X-100 for $15 \mathrm{~min}$ (at room temperature) and blocked with $5 \%$ fetal bovine 
A

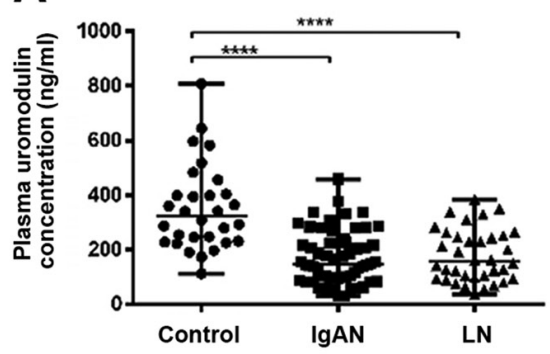

D

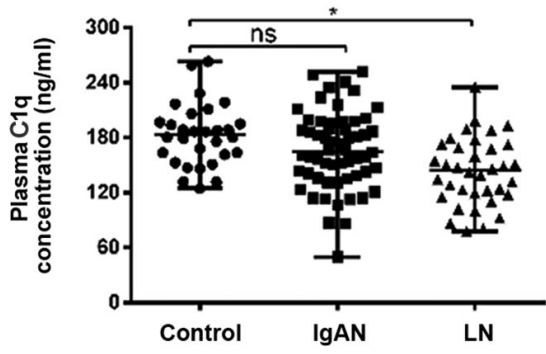

B

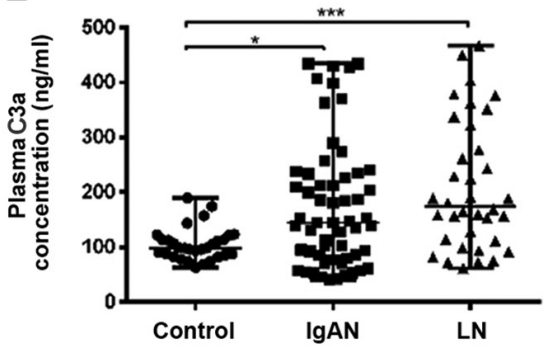

E

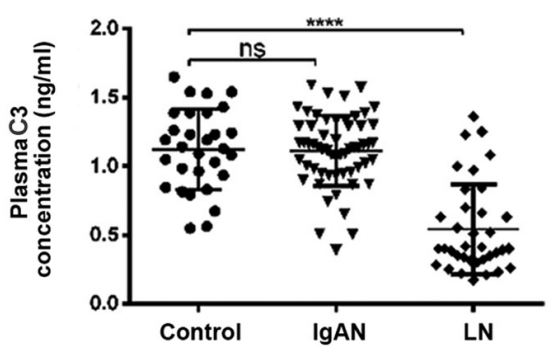

C

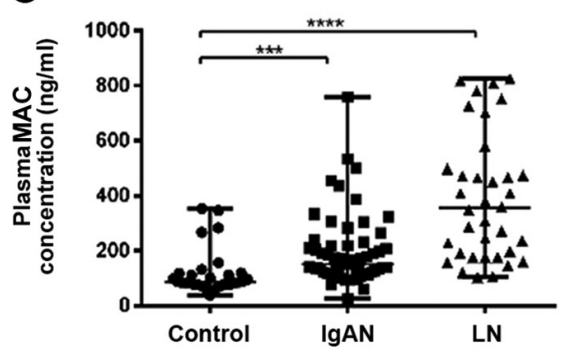

F

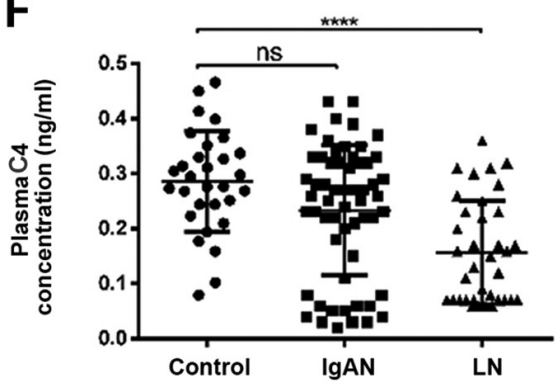

Figure 1. Plasma levels of uromodulin and complement components in healthy controls, patients with IgAN and patients with LN. Plasma levels of (A) uromodulin, (B) C3a, (C) MAC, (D) C1q, (E) C3 and (F) C4 in healthy control (n=30), IgAN (n=58) and LN (n=36) groups were analyzed using ELISA. Data are presented as the median and interquartile range. ${ }^{*} \mathrm{P}<0.05,{ }^{* *} \mathrm{P}<0.01,{ }^{* * * *} \mathrm{P}<0.001$ and ${ }^{* * * * *} \mathrm{P}<0.0001$. ns, not significant; MAC, membrane attack complex; LN, lupus nephritis; IgAN, IgA nephropathy.

serum (Gibco; Thermo Fisher Scientific, Inc.) for $30 \mathrm{~min}$ at room temperature. The cells were incubated with anti-C3d primary antibody (1:50; cat. no. AF2655-SP; R\&D Systems, Inc.) overnight at $4^{\circ} \mathrm{C}$. After washing, cells were incubated with secondary antibodies (1:200; cat. no. 34312ES60; Shanghai Yeasen Biotechnology Co., Ltd.) at room temperature for $1 \mathrm{~h}$ and DAPI was added dropwise to completely cover the cells for nuclei staining. The coverslip with cells was inversely placed and mounted on a slide with anti-fluorescence quenching agent (Beijing Solarbio Science \& Technology Co., Ltd.). Sections were evaluated under fluorescence microscopy (magnification, $\mathrm{x} 200$ ).

Statistical analysis. Data were analyzed using SPSS 23.0 software (IBM Corp.). Data are presented as the mean \pm SD of at least three experiments, median and interquartile range for continuous variables or numbers (proportions) for categorical variables. Kruskal-Wallis test was used for comparisons of UMOD and complement components levels in plasma of patients, and Dunn-Bonferroni test was used as the post-hoc test. The correlation between plasma UMOD levels and complement components levels or clinicopathological features were examined using Spearman's correlation analysis or $\chi^{2}$ test and Fisher's exact test, respectively. $\mathrm{P}<0.05$ was considered to indicate a statistically significant difference.

\section{Results}

Clinical characteristics of patients. Demographic and clinicopathological characteristics of the patients are presented in Table I. The median age of the patients with IgAN (33 years) and patients with LN (34 years) was not markedly different compared with that of healthy controls (41 years). Sex distribution was markedly different among the three groups. The immunofluorescence staining results of $\operatorname{IgA}, \operatorname{IgG}, \mathrm{C} 1 \mathrm{q}, \mathrm{C} 3$, IgM and Fibrinogen are presented in Table II.; IgA expression $(+++)$ occurred more frequently in $\operatorname{IgAN}$ than in $\mathrm{LN}$. IgG (+++) and C1q (+++) were expressed in $\mathrm{LN}$, but not in IgAN. The histopathological features of patients with IgAN and patients with LN are listed in Tables III and IV.

Levels of plasma UMOD and complement components in healthy controls, patients with IgAN and patients with $L N$. To investigate the potential association between UMOD and complement components, the levels of plasma UMOD, C3a, MAC, Clq, C3 and C4 in patients with IgAN or LN and healthy controls were analyzed in plasma samples using ELISA. It was revealed that the plasma UMOD concentration was significantly decreased in patients with $\operatorname{Ig} \mathrm{AN}$ or LN compared with in healthy controls $(\mathrm{P}<0.0001$; Fig. 1A). The plasma levels of $\mathrm{C} 3 \mathrm{a}$ and $\mathrm{MAC}$ in the three groups are shown in Fig. $1 \mathrm{~B}$ and $\mathrm{C}$. Compared with in the control group, C3a and MAC levels were significantly higher in the $\operatorname{IgAN}$ and $\mathrm{LN}$ groups $(\mathrm{P}<0.05$; Fig. 1B and C). Furthermore, the levels of C1q, C3 and C4 in plasma were significantly decreased in the LN group compared with in the control groups $(\mathrm{P}<0.05$ and $\mathrm{P}<0.0001$, respectively; Fig. 1D-F). However, there was no significant difference in the plasma levels of C1q, C3 and C4 between the IgAN and healthy control groups ( $\mathrm{P}>0.05$; Fig. 1D-F).

Correlation between UMOD levels and complement components. To further assess whether the levels of plasma UMOD were correlated with complement components, the Spearman correlation coefficients of all patients were calculated. The results indicated that the plasma levels of UMOD were significantly negatively correlated with the plasma concentration of $\mathrm{C} 3 \mathrm{a}$ and MAC ( $\mathrm{r}=-0.410$ and $\mathrm{P}<0.001 ; \mathrm{r}=-0.301$ and $\mathrm{P}=0.003$, respectively; Fig. $2 \mathrm{~A}$ and $\mathrm{B}$ ). 
Table I. Demographic, clinical and laboratory characteristics of patients with $\operatorname{Ig} A N(n=58), \operatorname{LN}(n=36)$ and healthy volunteers $(n=30)$.

\begin{tabular}{|c|c|c|c|c|}
\hline Characteristics & Total & $\operatorname{Ig} \mathrm{AN}$ & $\mathrm{LN}$ & Healthy volunteers \\
\hline Males, n (\%) & $45(47.9)$ & $38(65.5)$ & $7(19.4)$ & $15(50)$ \\
\hline Females, n (\%) & $49(52.1)$ & $20(34.5)$ & $29(80.6)$ & $15(50)$ \\
\hline Age, years (range) & $33(28-46)$ & $33(27-48)$ & $34(28-46)$ & $41(25-61)$ \\
\hline Height, $\mathrm{cm}$ (range) $\mathrm{cm}$ & $167.5(150-192)$ & $170(162-175)$ & $163(160-167)$ & $164.6(150-180)$ \\
\hline Weight, kg (range) & $69(60-75)$ & $71(64-78)$ & $65(59-70)$ & $64(46.5-92)$ \\
\hline $\mathrm{SBP}$ (range), $\mathrm{mmHg}$ & $137(128-154)$ & $137(128-153)$ & $137(129-153)$ & $134.5(107-184)$ \\
\hline $\mathrm{DBP} \pm \mathrm{SD}, \mathrm{mmHg}$ & $87.89 \pm 14.79$ & $87(77-95)$ & $90(78-98)$ & $85.56(69-114)$ \\
\hline $\mathrm{RBC} \pm \mathrm{SD}, \mathrm{x} 10^{12} / 1$ & $4.21 \pm 0.81$ & $4.49 \pm 0.66$ & $3.78 \pm 0.84$ & \\
\hline $\mathrm{HGB} \pm \mathrm{SD}, \mathrm{g} / \mathrm{l}$ & $121 \pm 25.8$ & $132 \pm 22.8$ & $105 \pm 21.8$ & $118 \pm 28$ \\
\hline $\mathrm{ESR}$ (range), mm/h & $19(11-32)$ & $17(10-23)$ & $26(13-48)$ & $34(18-55)$ \\
\hline Total protein (range), g/l & $58.7(47.9-66.3)$ & $61.2(52.47-66.8)$ & $50.2(37.28-64.57)$ & $59.6(48.7-76.8)$ \\
\hline Albumin (range), g/l & $33.25(25.2-39.93)$ & $35.55(30.7-42.03)$ & $27.95(18.83-33.25)$ & $32.62(15.7-41.4)$ \\
\hline ALT (range), U/l & $15(11-19)$ & $15(11-18)$ & $15(11-22)$ & $19.7(5-35)$ \\
\hline AST (range), U/1 & $18(15-22)$ & $18(16-22)$ & $19(15-26)$ & $20.2(11-26)$ \\
\hline $\begin{array}{l}\text { Total cholesterol (range), } \\
\mathrm{mmol} / \mathrm{l}\end{array}$ & $5.64(4.47-6.63)$ & $5.48(4.63-6.59)$ & $5.73(3.77-7.19)$ & $5.16(3.13-9.19)$ \\
\hline $\begin{array}{l}\text { HDL cholesterol } \pm \text { SD, } \\
\mathrm{mmol} / 1\end{array}$ & $1.32 \pm 0.34$ & $1.32 \pm 0.30$ & $1.31 \pm 0.40$ & $1.32 \pm 0.39$ \\
\hline $\begin{array}{l}\text { LDL cholesterol (range), } \\
\mathrm{mmol} / 1\end{array}$ & $3.35(2.41-4.13)$ & $3.30(2.60-4.09)$ & $3.56(2.20-4.23)$ & $3.15(2.09-4.88)$ \\
\hline $\begin{array}{l}\text { Triglycerides (range), } \\
\mathrm{mmol} / \mathrm{l}\end{array}$ & $2.02(1.33-2.83)$ & $1.93(1.22-2.72)$ & $2.17(1.45-3.16)$ & $1.87(0.97-3.17)$ \\
\hline Creatinine (range), mg/dl & $95(73.75-134.25)$ & 107 (79-139.5) & $91(68.25-131.25)$ & $126.4(77-287)$ \\
\hline BUN (range), $\mu \mathrm{mol} / 1$ & $6.57(5.1-11.23)$ & $5.78(4.79-7.83)$ & $9.38(6-16.15)$ & $7.81(5.1-13.21)$ \\
\hline Cystatin C (range), mg/l & $1.43(1.03-1.86)$ & $1.16(0.94-1.67)$ & $1.67(1.16-2.43)$ & $1.58(0.74-2.42)$ \\
\hline Uric acid (range), $\mu \mathrm{mol} / 1$ & $393(311-523)$ & 373 (294-470) & $430(344-572)$ & $359.3(239-420)$ \\
\hline $\begin{array}{l}\text { eGFR (range) } \\
\mathrm{ml} / \mathrm{min} / 1.73 \mathrm{~m}^{2}\end{array}$ & $92(72-110)$ & $97(82-110)$ & $86(66-107)$ & $90(64-112)$ \\
\hline $\mathrm{GLU} \pm \mathrm{SD}, \mathrm{mmol} / \mathrm{l}$ & $4.56 \pm 0.69$ & $4.56 \pm 0.58$ & $4.56 \pm 0.84$ & $4.44 \pm 0.75$ \\
\hline UACR (range), mg/g & $2.65(1.28-3.82)$ & $2.16(1.08-3.43)$ & $2.95(1.73-7.45)$ & $2.49(0.99-4.49)$ \\
\hline C3a (range), ng/l & $157.6(92.4-240.4)$ & $144.8(79.2-233.9)$ & $175(112.5-310.6)$ & $147(60.9-277.1)$ \\
\hline MAC (range), ng/l & $190.8(135.5-364.9)$ & $150.7(117.4-222.2)$ & $354.4(179.8-491)$ & $281(118.76-435.7)$ \\
\hline $\mathrm{C} 1 \mathrm{q} \pm \mathrm{SD}, \mathrm{mg} / \mathrm{l}$ & $157 \pm 41.4$ & $165 \pm 42.1$ & $143 \pm 36.5$ & $169 \pm 43.4$ \\
\hline C3 (range), g/l & $0.98(0.5-1.18)$ & $1.14(0.96-1.29)$ & $0.4(0.31-0.69)$ & $0.9(0.26-1.57)$ \\
\hline C4 (range), g/l & $0.22(0.07-0.30)$ & $0.26(0.14-0.32)$ & $0.14(0.07-0.23)$ & $0.25(0.067-0.533)$ \\
\hline UMOD (range) ng/l & $149.88(96.53-245.04)$ & $147.12(96.53-230.44)$ & $156.79(95.42-250.25)$ & $189.91(80.27-231.23)$ \\
\hline $\mathrm{K} \pm \mathrm{SD}, \mathrm{mmol} / \mathrm{l}$ & $4.19 \pm 0.56$ & $4.16 \pm 0.50$ & $4.23 \pm 0.71$ & $8.58 \pm 0.24$ \\
\hline $\mathrm{Na}$ (range), mmol/l & $141(139-143)$ & $142(141-143)$ & $140(138-142)$ & $138.3(123-143)$ \\
\hline $\mathrm{Cl} \pm \mathrm{SD}, \mathrm{mmol} / \mathrm{l}$ & $106 \pm 3.6$ & $106 \pm 2.6$ & $106 \pm 4.9$ & $102 \pm 1.9$ \\
\hline
\end{tabular}

SBP, systolic blood pressure; DBP, diastolic blood pressure; RBC, Red blood cell; HGB, Hemoglobin; ESR, erythrocyte sedimentation rate; ALT, alanine transaminase; AST, Aspartate aminotransferase; HDL, High-density lipoprotein; LDL, Low-density lipoprotein; BUN, blood urea nitrogen; GLU, Glucose; UACR, urine albumin/creatinine ratio; IgAN, IgA nephropathy; LN, lupus nephritis; MAC, membrane attack complex; UMOD, uromodulin; eGFR, estimated glomerular filtration rate. Age is presented as the median value for all the variables.

Subsequently, the correlation of plasma levels of C1q, C3 and $\mathrm{C} 4$ with plasma UMOD was investigated in all patients. It was demonstrated that the plasma levels of UMOD were significantly positively correlated with the plasma concentration of $\mathrm{Clq}$ ( $\mathrm{r}=0.283$; $\mathrm{P}=0.006$; Fig. 2C), However, plasma UMOD levels were not significantly correlated with C3
( $\mathrm{r}=0.147 ; \mathrm{P}=0.157$; Fig. 2D) and $\mathrm{C} 4$ ( $\mathrm{r}=0.195 ; \mathrm{P}=0.06$; Fig. 2E). In addition, the simulated $\mathrm{H} / \mathrm{R}$ model was used to assess these correlation coefficients in mIMCD3 cells. Compared with the control group, the protein expression levels of complement $\mathrm{ClqA}$ decreased at $1 \mathrm{~h}$ after $\mathrm{H} / \mathrm{R}$ and began to increase at $6 \mathrm{~h}$ after H/R, but no significant change was observed a12 h after 

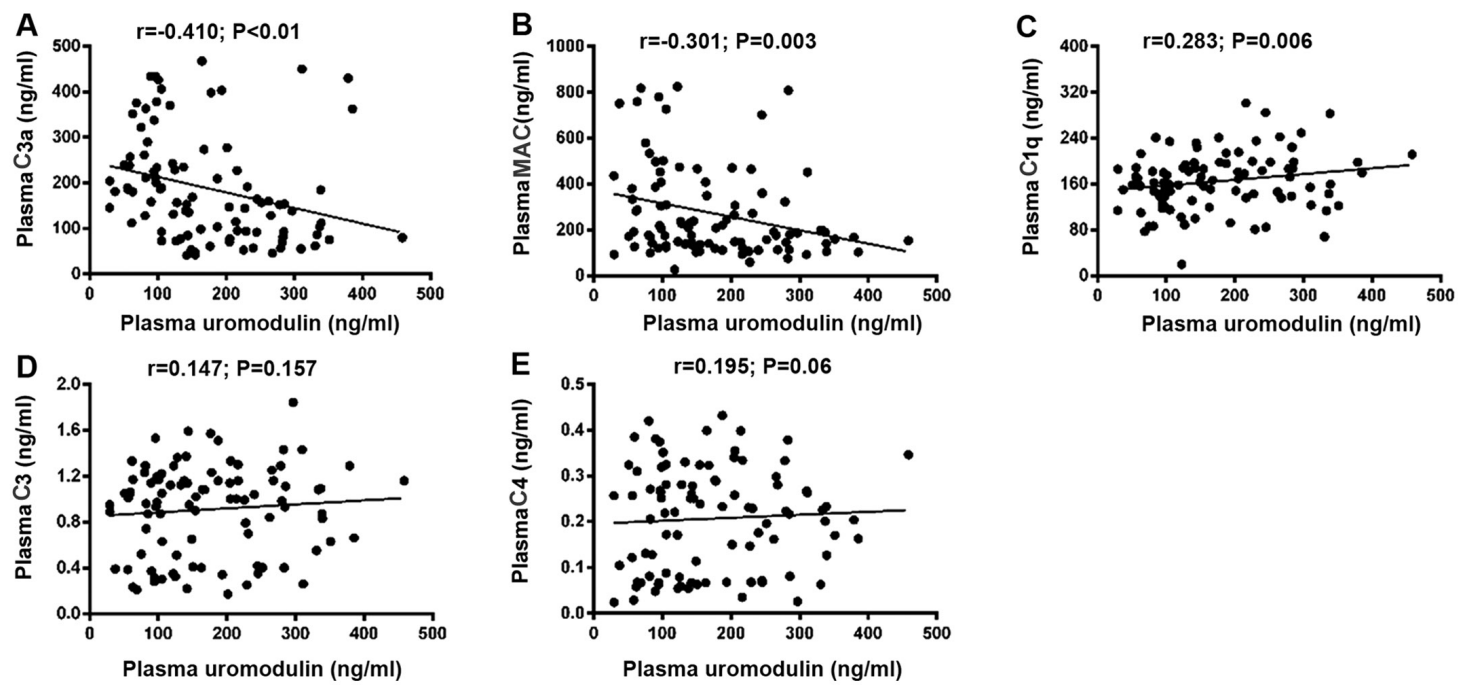

Figure 2. Correlation between plasma uromodulin and complement components. Correlation between plasma uromodulin and plasma (A) C3a, (B) MAC, (C) C1q, (D) C3 and (E) C4. MAC, membrane attack complex.

Table II. Histological characteristics of patients with IgAN $(n=58)$ and $\mathrm{LN}(\mathrm{n}=36)$.

\begin{tabular}{|c|c|c|c|}
\hline $\begin{array}{l}\text { Immuno- } \\
\text { fluorescence } \\
\text { staining }\end{array}$ & $\begin{array}{l}\text { Total, } \\
\mathrm{n}(\%)\end{array}$ & $\begin{array}{l}\text { IgAN, } \\
\text { n }(\%)\end{array}$ & $\begin{array}{c}\mathrm{LN}, \\
\mathrm{n}(\%)\end{array}$ \\
\hline \multicolumn{4}{|l|}{$\operatorname{Ig} \mathrm{A}$} \\
\hline- & $3(3.2)$ & $0(0.0)$ & $3(8.3)$ \\
\hline+ & $13(13.8)$ & $5(8.6)$ & 8 (22.2) \\
\hline++ & $22(23.4)$ & $10(17.2)$ & $12(33.3)$ \\
\hline+++ & $56(59.6)$ & $43(74.1)$ & $13(36.1)$ \\
\hline \multicolumn{4}{|l|}{$\operatorname{IgG}$} \\
\hline- & $51(54.3)$ & $48(82.9)$ & $3(8.3)$ \\
\hline+ & $17(18.1)$ & $9(15.5)$ & $8(22.2)$ \\
\hline++ & $13(13.8)$ & $1(1.7)$ & $12(33.3)$ \\
\hline+++ & $13(13.8)$ & $0(0.0)$ & $13(36.1)$ \\
\hline \multicolumn{4}{|l|}{ C3 } \\
\hline- & $21(22.3)$ & $19(32.8)$ & $2(5.6)$ \\
\hline+ & $17(18.1)$ & $12(20.7)$ & 3 (13.9) \\
\hline++ & $21(22.3)$ & $11(19.0)$ & $10(27.8)$ \\
\hline+++ & $35(37.2)$ & $16(27.6)$ & $19(52.8)$ \\
\hline \multicolumn{4}{|l|}{$\mathrm{C} 1 \mathrm{q}$} \\
\hline- & $46(48.9)$ & $44(75.9)$ & $2(5.6)$ \\
\hline+ & $18(19.1)$ & $11(19.0)$ & 7 (19.4) \\
\hline++ & $13(13.8)$ & $3(5.2)$ & $10(27.8)$ \\
\hline+++ & $17(18.1)$ & $0(0.0)$ & $17(47.2)$ \\
\hline \multicolumn{4}{|l|}{$\operatorname{IgM}$} \\
\hline- & $32(34)$ & 27 (46.6) & $5(13.9)$ \\
\hline+ & $23(24.5)$ & $16(27.6)$ & 7 (19.4) \\
\hline++ & $28(29.8)$ & $11(19.0)$ & $17(47.2)$ \\
\hline+++ & $11(11.7)$ & $4(6.9)$ & 7 (19.4) \\
\hline \multicolumn{4}{|l|}{ Fibrinogen } \\
\hline- & $51(54.3)$ & $44(75.9)$ & 7 (19.4) \\
\hline+ & $10(10.6)$ & $2(3.4)$ & $8(22.2)$ \\
\hline++ & $20(21.3)$ & $7(12.1)$ & $13(36.1)$ \\
\hline+++ & $13(13.8)$ & $5(8.6)$ & $8(22.2)$ \\
\hline
\end{tabular}

IgAN, IgA nephropathy; LN, lupus nephritis.
H/R compared with $6 \mathrm{~h}$ after H/R (Fig. 3A). On the other hand, the protein expression levels of UMOD started to increase at $1 \mathrm{~h}$ after $\mathrm{H} / \mathrm{R}$ treatment, and continued to increase at 6 and $12 \mathrm{~h}$ after H/R (Fig. 3A and B). In addition, the expression levels of the complement activation product $\mathrm{C} 3 \mathrm{~d}$ on the surface of the cell membrane was measured via immunofluorescence staining, revealing that $\mathrm{C} 3 \mathrm{~d}$ expression was increased at $1 \mathrm{~h}$ and began to decrease at $6 \mathrm{~h}$ after H/R (Fig. 3C). No significant change was observed at $12 \mathrm{~h}$ compared with $6 \mathrm{~h}$ post H/R (data not shown).

Association between plasma UMOD levels and clinicopathological variables. To determine whether plasma UMOD expression was associated with clinicopathological parameters, kidney function parameters and histopathological stage were analyzed in all patients. As shown in Fig. 4A-D, plasma UMOD concentration was closely correlated with the following kidney function biomarkers: eGFR ( $\mathrm{r}=0.255$; $\mathrm{P}=0.013$; Fig. 4A), creatinine ( $\mathrm{r}=-0.307$; $\mathrm{P}=0.003$; Fig. 4B), BUN ( $\mathrm{r}=-0.359 ; \mathrm{P}<0.001$; Fig. 4C) and cystatin $\mathrm{C}(\mathrm{r}=-0.294$; $\mathrm{P}=0.004$; Fig. 4D). Based on the median expression levels of plasma UMOD in the IgAN groups, patients were classified into two subgroups: Low and high expression group. In patients with IgAN, the plasma levels of UMOD were significantly associated with tubular atrophy and interstitial fibrosis ( $\mathrm{P}=0.0219$; Table III). In addition, it was revealed that in patients with LN plasma UMOD expression was significantly associated with AI ( $\mathrm{P}=0.0354$; Table IV). No other clinicopathological feature was identified to be associated with plasma UMOD expression.

\section{Discussion}

In present study, it was demonstrated that UMOD was negatively and significantly correlated with complement activation product $\mathrm{C} 3 \mathrm{a}$ and $\mathrm{MAC}$ in patients with $\operatorname{IgAN}$ and $\mathrm{LN}$. Moreover, UMOD was positively correlated with complement components $\mathrm{Clq}$ in the IgAN group. This correlation was further assessed using a simulated $\mathrm{H} / \mathrm{R}$ model in vitro. 
Table III. Pathological characteristics of 58 patients with IgA nephropathy with high (n=29) and low (n=29) uromodulin expression according to the Oxford classification.

Uromodulin expression, $\mathrm{n}(\%)$

\begin{tabular}{lrrrr} 
Characteristics & $\mathrm{N}$ & High & Low & P-value \\
\hline Mesangial hypercellularity & & & & \\
$\quad$ M0 & 34 & $18(52.9)$ & $16(47.1)$ & 0.7901 \\
M1 & 24 & $11(45.8)$ & $13(54.2)$ & \\
Endocapillary hypercellularity & & & & \\
E0 & 26 & $15(57.7)$ & $11(42.3)$ & 0.4287 \\
E1 & 32 & $14(43.8)$ & $18(56.2)$ & \\
Segmental glomerulosclerosis & & & & \\
S0 & 8 & $3(37.5)$ & $5(62.5)$ & 0.7057 \\
S1 & 50 & $26(52.0)$ & $24(48.0)$ & \\
Tubular atrophy/interstitial fibrosis & & & & \\
T0 & 33 & $21(63.6)$ & $12(36.4)$ & \\
T1 & 21 & $8(38.1)$ & $13(61.9)$ & \\
T2 & 4 & $0(0.0)$ & $4(100.0)$ & \\
\hline
\end{tabular}

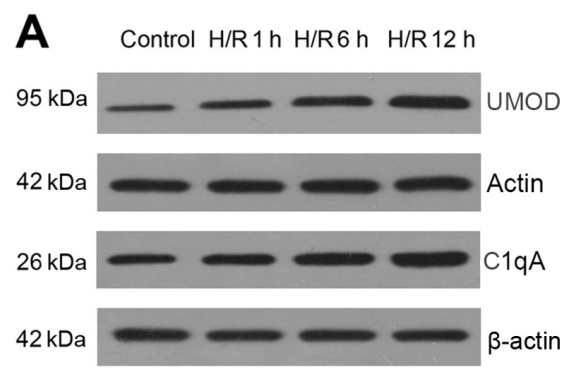

B
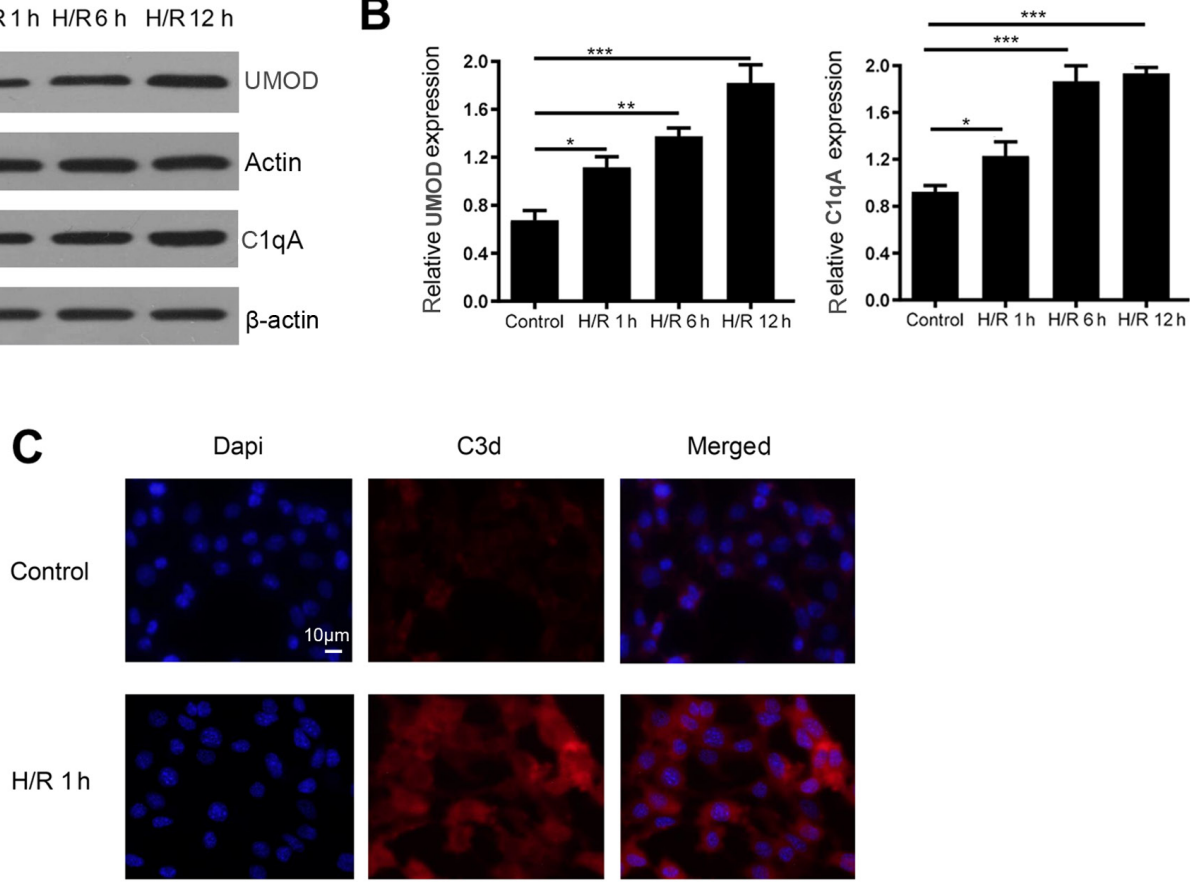

H/R $6 \mathrm{~h}$
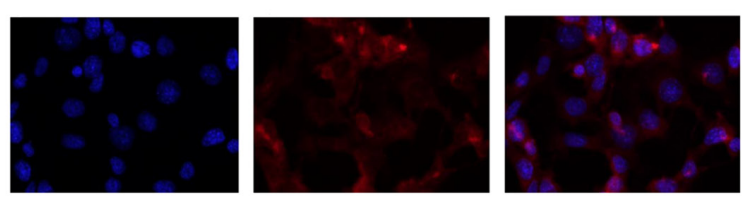

Figure 3. H/R model stimulation of UMOD expression and its effect on complement ClqA and C3d expression in mouse inner medullary collecting duct cells. (A) Protein expression levels of complement ClqA and UMOD at different times after H/R exposure. (B) Relative signal intensity of UMOD protein expression was normalized to $\beta$-actin and quantified using ImageJ software. Data are presented as the mean \pm SD from three individual experiments. (C) Expression of complement activation product $\mathrm{C} 3 \mathrm{~d}$ on the cell surface was detected using immunofluorescence. Magnification, $\mathrm{x} 200 .{ }^{*} \mathrm{P}<0.05 ;{ }^{* * *} \mathrm{P}<0.01 ;{ }^{* * * *} \mathrm{P}<0.001$. $\mathrm{H} / \mathrm{R}$, hypoxia-reoxygenation; UMOD, uromodulin.

Previous studies have reported that UMOD expression is closely associated with kidney diseases (3-9). It has been demonstrated that UMOD gene mutations result in familial juvenile hyperuricemic nephropathy, medullary cystic kidney disease type 2 and glomerulocystic kidney disease (8). Furthermore, UMOD-deficient mice are more susceptible 
Table IV. Pathological characteristics of 36 patients with lupus nephritis with high $(\mathrm{n}=18)$ and low $(\mathrm{n}=18)$ uromodulin expression.

Uromodulin expression, $\mathrm{n}(\%)$

Characteristics

High

Low

P-value

Histological classification

II+III

$\mathrm{IV}+\mathrm{V}$

$12(41.4)$

17 (58.6)

Activity index

$\begin{array}{ll}<10 & 23 \\ \geq 10 & 13\end{array}$

$3(23.1) \quad 10(76.9)$

Chronicity index

\begin{tabular}{|c|c|c|c|c|}
\hline$<3$ & 24 & $14(58.3)$ & $10(41.6)$ & 0.2890 \\
\hline$\geq 3$ & 12 & $4(33.3)$ & $8(66.7)$ & \\
\hline
\end{tabular}

A

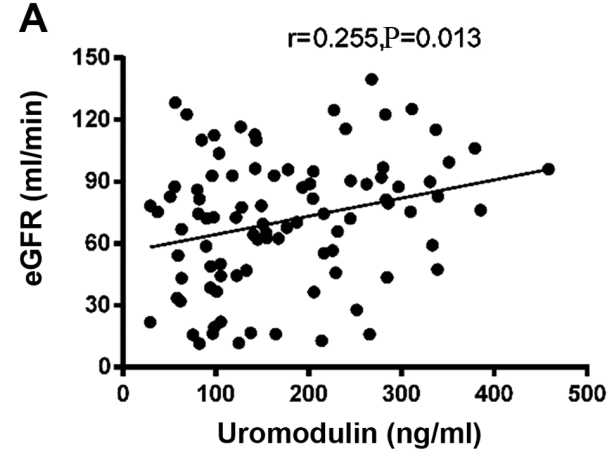

C

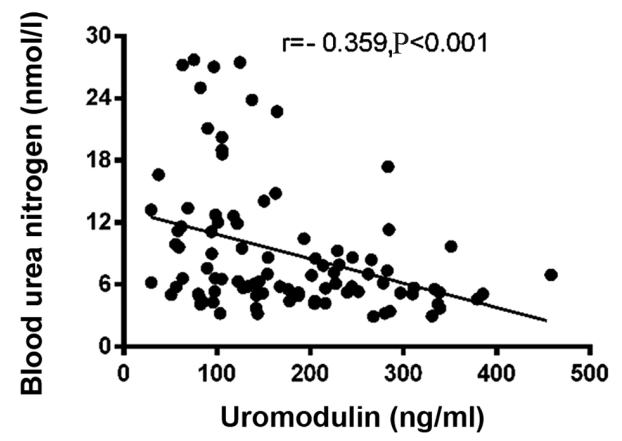

B

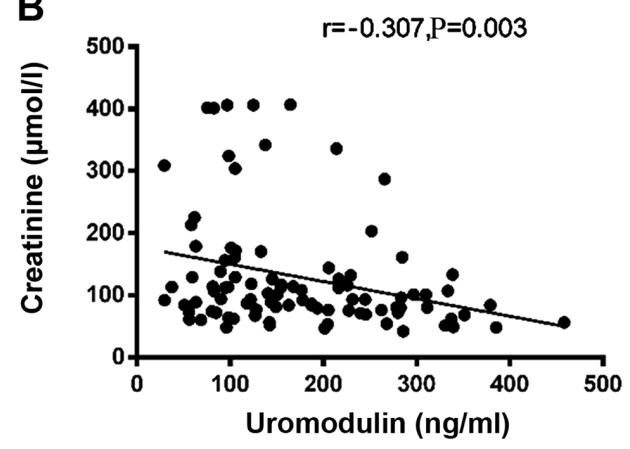

D

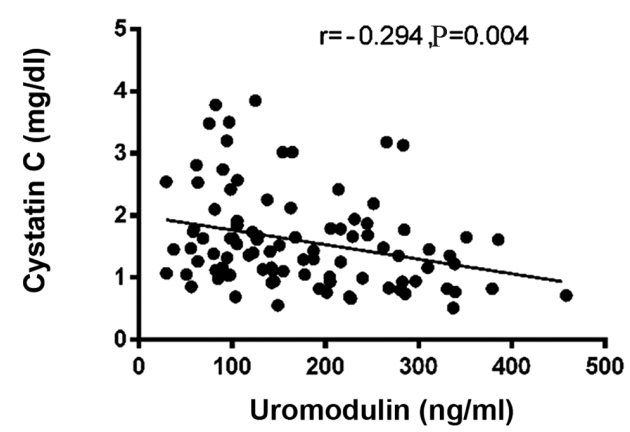

Figure 4. Correlation between plasma uromodulin and kidney function parameters. Correlation between plasma uromodulin and (A) eGFR, (B) serum creatinine, (C) blood urea nitrogen and (D) serum cystatin C. eGFR, estimated glomerular filtration rate.

to nephrolithiasis (9). Serum UMOD is a promising potential biomarker in the progression of renal disease (29). Mechanistically, the role of UMOD is associated with renal ion channel activity $(9,30)$, urinary tract infections (31) and urinary cast formation (32). $\mathrm{UMOD}^{-/-}$mice exhibit a decrease in renal outer medullary potassium channel (ROMK) immunoreactivity in the plasma membrane-enriched fractions and an increase of ROMK accumulation in intracellular vesicular compartments compared with wild-type mice $(33,34)$. Moreover, in a previous study, $>100 \mu \mathrm{g} / \mathrm{ml}$ UMOD predominantly prevented the adherence of Escherichia coli to transitional cells $(35,36)$. Additionally, UMOD is involved in the gel and potential cast formation in acute tubular necrosis partially via oligosaccharide residues (37). Consistent with previous studies (10-12), the present study identified the potential association between UMOD and kidney diseases, and revealed that plasma UMOD levels were decreased in patients with IgAN and LN. This may be associated with interstitial fibrosis, renal tubular atrophy and decreased EGFR, which is consistent with previous reports on the decrease of urinary UMOD levels in patients with IgAN (10-12).

Complement is an important component of the immune system, and complement components are produced by kidney parenchymal tissues, as well as the liver. Moreover, the complement system is involved in various renal disease, such as LN (38), IgAN (39) and diabetic nephropathy (40). 
Individuals with homozygous hereditary deficiency of the classical pathway components, such as C1q, C1r, C1s, C4 and $\mathrm{C} 2$, are more susceptible to systemic lupus erythematosus (41). In addition, complement activation promotes the pathogenesis of IgAN via alternative and lectin pathways, and likely occurs systemically on $\operatorname{IgA}$-containing circulating immune complexes, as well as locally in glomeruli (42). A clinical study has reported that the $\mathrm{Clq}$, mannose-binding lectin, $\mathrm{Bb}$, C4d, C3a, C5a and sC5b-9 levels in the plasma of patients with diabetic nephropathy are significantly higher than in the plasma of patients with diabetes without renal disease (43). Mechanically, activation of the lectin and alternative pathways of the three possible complement pathways is associated with renal damage (21). In accordance with the aforementioned findings, the present results indicated that $\mathrm{C} 3 \mathrm{a}$ and MAC levels were increased in the plasma of patients with $\operatorname{Ig} \mathrm{AN}$ and LN.

UMOD is considered to be a component of the innate immune system $(42,43)$, and it has been revealed that UMOD binds with immune proteins, such as IgG28, complement factors, such as C1q $(34,35)$, cytokines and TNFa (36). In addition, our previous study has reported that UMOD significantly enhances the function of complement $\mathrm{H}$ factor cleavage of $\mathrm{C} 3 \mathrm{~b}$ and inhibits complement activation (44). Collectively, the aforementioned findings suggest that UMOD is closely associated with complement activation. However, the association between UMOD and complement components remains unknown. In the present study, it was identified that UMOD participated in the progression of kidney disease, which was partially dependent on complement activation.

Although the clinical significance of UMOD and complement activation in renal disease has been clarified, there are several limitations to the present study that warrant discussion. Firstly, the number of patients enrolled in the current study was small. Secondly, the underlying mechanism is still unclear. The study confirmed that UMOD was involved in the progression of renal disease, which partly depended on the activation of complement. Whether UMOD promoted the activation of complement by binding to complement factor $\mathrm{C} 1 \mathrm{q}$ protein and then promote the progress of $\operatorname{Ig} \mathrm{AN}$ and $\mathrm{LN}$ in renal disease, needed further investigated in future studies. In addition, functional studies should be performed to identify the biological mechanisms of UMOD in renal disease.

In conclusion, the present results suggested that low UMOD plasma levels were associated with severe complement activation and may be involved in complement-mediated immune protection by inhibiting complement activation in in renal disease.

\section{Acknowledgements}

Not applicable.

\section{Funding}

The present study was supported by the National Youth Science Foundation Project (grant no. 81700622).

\section{Availability of data and materials}

The datasets used and/or analyzed during the current study are available from the corresponding author on reasonable request.

\section{Authors' contributions}

XY designed the study and revised the manuscript. FS and ML performed the experiments. FP and LY analyzed the data. FP provided technical support. LY drafted the manuscript. XY and FP confirm the authenticity of all the raw data. All authors have read and approved the final manuscript.

\section{Ethics approval and consent to participate}

The present study was approved by the Ethics Committee of Qi Lu Hospital of Shandong University (Jinan, China; approval no. KYLL-2017-004), and written informed consent was obtained from all patients and healthy controls.

\section{Patient consent for publication}

Not applicable.

\section{Competing interests}

The authors declare that they have no competing interests.

\section{References}

1. Reindl J, Gröne HJ, Wolf G and Busch M: Uromodulin-related autosomal-dominant tubulointerstitial kidney disease-pathogenetic insights based on a case. Clin Kidney J 12: 172-179, 2018.

2. Vikulova OK, Zuraeva ZT, Mikhaleva OV, Nikankina LV, Shamkhalova MS, Shestakova MV and Dedov II: Renal effects of glucagon-like peptide receptor agonists in patients with type 1 diabetes mellitus. Ter Arkh 90: 59-64, 2018.

3. Bennett MR, Pyles O, Ma Q and Devarajan P: Preoperative levels of urinary uromodulin predict acute kidney injury after pediatric cardiopulmonary bypass surgery. Pediatr Nephrol 33: 521-526, 2018.

4. Smirnov AV, Khasun M, Kayukov IG, Galkina OV, Sipovski VG, Parastaeva MM and Bogdanova EO: Serum uromodulin as an early biomarker of tubular atrophy and interstitial fibrosis in patients with glomerulopathies. Ter Arkh 90: 41-47, 2018.

5. Devuyst $\mathrm{O}$ and Pattaro C: The UMOD Locus: Insights into the pathogenesis and prognosis of kidney disease. J Am Soc Nephrol 29: 713-726, 2018.

6. Lhotta K: Uromodulin and chronic kidney disease. Kidney Blood Press Res 33: 393-398, 2010.

7. Kuśnierz-Cabala B, Gala-Błądzińska A, Mazur-Laskowska M, Dumnicka P, Sporek M, Matuszyk A, Gil K, Ceranowicz P, Walocha J, Kucharz J, et al: Serum uromodulin levels in prediction of acute kidney injury in the early phase of acute pancreatitis. Molecules 22: 22, 2017.

8. Leiherer A, Muendlein A, Saely CH, Brandtner EM, Geiger K, Fraunberger $\mathrm{P}$ and Drexel $\mathrm{H}$ : The value of uromodulin as a new serum marker to predict decline in renal function. J Hypertens 36 : 110-118, 2018.

9. Micanovic R, LaFavers K, Garimella PS, Wu XR and El-Achkar TM: Uromodulin (Tamm-Horsfall protein): Guardian of urinary and systemic homeostasis. Nephrol Dial Transplant 35: 33-43, 2020.

10. Lv L, Wang J, Gao B, Wu L, Wang F, Cui Z, He K, Zhang L, Chen $\mathrm{M}$ and Zhao MH: Serum uromodulin and progression of kidney disease in patients with chronic kidney disease. J Transl Med 16: 316, 2018.

11. Micanovic R, Khan S, Janosevic D, Lee ME, Hato T, Srour EF, Winfree S, Ghosh J, Tong Y, Rice SE et al: Tamm-horsfall protein regulates mononuclear phagocytes in the kidney. J Am Soc Nephrol 29: 841-856, 2018.

12. Skowron B, Baranowska A, Dobrek L, Ciesielczyk K, Kaszuba-Zwoinska J, Wiecek G, Malska-Wozniak A, Strus M and Gil K: Urinary neutrophil gelatinase-associated lipocalin, kidney injury molecule-1, uromodulin, and cystatin $C$ concentrations in an experimental rat model of ascending acute kidney injury induced by pyelonephritis. J Physiol Pharmacol 69: 625-637, 2018. 
13. Martín-Gómez MA, Eliecer C,Caba Molina M, González Oller C and García Del Moral R: Familial hyperuricaemic nephropathy: New mutation in uromodulin gen. Nefrol Engl Ed 39: 309-311, 2019.

14. Rhodes DCJ: Human Tamm-Horsfall protein, a renal specific protein, serves as a cofactor in complement $3 \mathrm{~b}$ degradation. PLoS One 12: e0181857, 2017

15. Lane BR, Babitz SK, Vlasakova K, Wong A, Noyes SL, Boshoven W, Pam Grady P, Zimmerman C, Engerman S, Gebben M, et al: Evaluation of urinary renal biomarkers for early prediction of acute kidney injury following partial nephrectomy: A feasibility study. Eur Urol Focus 6: 1240-1247, 2020.

16. Patidar KR, Garimella PS, Macedo E, Slaven JE, Ghabril MS, Weber RE, Anderson M, Orman ES, Nephew LD, Desai AP et al: Admission plasma uromodulin and the risk of acute kidney injury in hospitalized patients with cirrhosis: A pilot study. Am J Physiol Gastrointest Liver Physiol 317: G447-G452, 2019.

17. Tosukhowong P, Kulpradit P, Chaiyarit S, Ung jareonwattana W, Kalpongnukul N, Ratchanon S and Thongboonkerd V: Lime powder treatment reduces urinary excretion of total protein and transferrin but increases uromodulin excretion in patients with urolithiasis. Urolithiasis 46: 257-264, 2018

18. Gast C, Marinaki A, Arenas-Hernandez M, Campbell S, Seaby EG, Pengelly RJ, Gale DP, Connor TM, Bunyan DJ, Hodaňová K et al: Autosomal dominant tubulointerstitial kidney disease-UMOD is the most frequent non polycystic genetic kidney disease. BMC Nephrol 19: 301, 2018.

19. Tokonami N, Olinger E, Debaix H, Houillier P and Devuyst O The excretion of uromodulin is modulated by the calcium-sensing receptor. Kidney Int 94: 882-886, 2018.

20. Bullen AL, Katz R, Lee AK, Anderson CAM, Cheung AK, Garimella PS, Jotwani V, Haley WE, Ishani A, Lash JP et al: The SPRINT trial suggests that markers of tubule cell function in the urine associate with risk of subsequent acute kidney injury while injury markers elevate after the injury. Kidney Int 96: 470-479, 2019.

21. Scherberich JE, Gruber R, Nockher WA, Christensen EI, Schmitt H, Herbst V, Block M, Kaden J and Schlumberger W: Serum uromodulin-a marker of kidney function and renal parenchymal integrity. Nephrol Dial Transplant 33: 284-295, 2018

22. Wiromrat P, Bjornstad P, Roncal C, Pyle L, Johnson RJ Cherney DZ, Lipina T, Bishop F, Maahs DM and Wadwa RP: Serum uromodulin is associated with urinary albumin excretion in adolescents with type 1 diabetes. J Diabetes Complications 33: 648-650, 2019.

23. Schiano G, Glaudemans B, Olinger E, Goelz N, Müller M, Loffing-Cueni D, Deschenes G, Loffing J and Devuyst O: The urinary excretion of uromodulin is regulated by the potassium channel ROMK. Sci Rep 9: 19517, 2019.

24. Cañadas-Garre M, Anderson K, McGoldrick J, Maxwell AP and McKnight AJ: Proteomic and metabolomic approaches in the search for biomarkers in chronic kidney disease. J Proteomics 193: 93-122, 2019.

25. Graham LA, Aman A, Campbell DD, Augley J, Graham D, McBride MW, Fraser NJ, Ferreri NR, Dominiczak AF and Padmanabhan S: Salt stress in the renal tubules is linked to TAL-specific expression of uromodulin and an upregulation of heat shock genes. Physiol Genomics 50: 964-972, 2018.

26. Song H, Hu H, Tang F, Cao C, Wan Q and He Y: Initial serum creatinine concentration affects clinical outcomes in patients with IgA nephropathy treated with mycophenolate mofetil combined with low-dose prednisone. Exp Ther Med 19: 3369-3376, 2020.

27. Hwang J, Kim HJ, Oh JM, Ahn JK, Lee YS, Lee J, Kim YG, Huh WS, Seo J, Koh EM et al: Outcome of reclassification of World Health Organization (WHO) class III under International Society of Nephrology-Renal Pathology Society (ISN-RPS) classification: Retrospective observational study. Rheumatol Int 32 $1877-1884,2012$.

28. Chen Y, Harty GJ, Zheng Y, Iyer SR, Sugihara S, Sangaralingham SJ, Ichiki T, Grande JP, Lee HC, Wang X et al: CRRL269. Circ Res 124: 1462-1472, 2019.
29. Bostom A, Steubl D, Garimella PS, Franceschini N, Roberts MB, Pasch A, Ix JH, Tuttle KR, Ivanova A, Shireman T et al: Serum uromodulin: A biomarker of long-term kidney allograft failure. Am J Nephrol 47: 275-282, 2018.

30. Steubl D, Buzkova P, Ix JH, Devarajan P, Bennett MR, Chaves PH, Shlipak MG, Bansal N, Sarnak MJ and Garimella PS: Association of serum and urinary uromodulin and their correlates in older adults-The Cardiovascular Health Study. Nephrology (Carlton) 25: 522-526, 2020

31. Nie M, Bal MS, Liu J, Yang Z, Rivera C, Wu XR, Hoenderop JG, Bindels RJ, Marciano DK and Wolf MT: Uromodulin regulates renal magnesium homeostasis through the ion channel transient receptor potential melastatin 6 (TRPM6). J Biol Chem 293 16488-16502, 2018.

32. Tokonami N, Takata T, Beyeler J, Ehrbar I, Yoshifuji A, Christensen EI,Loffing J, Devuyst O and Olinger EG: Uromodulin is expressed in the distal convoluted tubule, where it is critical for regulation of the sodium chloride cotransporter NCC. Kidney Int 94: 701-715, 2018

33. Maydan O, McDade PG, Liu Y, Wu XR, Matsell DG and Eddy AA: Uromodulin deficiency alters tubular injury and interstitial inflammation but not fibrosis in experimental obstructive nephropathy. Physiol Rep 6: e13654, 2018

34. Yamamoto CM, Murakami T, Oakes ML, Mitsuhashi M, Kelly C, Henry RR and Sharma K: Uromodulin mRNA from urinary extracellular vesicles correlate to kidney function decline in type 2 diabetes mellitus. Am J Nephrol 47: 283-291, 2018.

35. Lin Z, Yang J, Liu H, Cai D, An Z, Yu Y and Chen T: A novel uromodulin mutation in autosomal dominant tubulointerstitial kidney disease: A pedigree-based study and literature review. Ren Fail 40: 146-151, 2018

36. Olinger E, Lake J, Sheehan S, Schiano G, Takata T, Tokonami N, Debaix H, Consolato F, Rampoldi L, Korstanje R et al: Hepsin-mediated processing of uromodulin is crucial for salt-sensitivity and thick ascending limb homeostasis. Sci Rep 9: 12287, 2019.

37. Bus P, Chua JS, Klessens CQF, Zandbergen M, Wolterbeek R, van Kooten C, Trouw LA, Bruijn JA and Baelde HJ: Complement activation in patients with diabetic nephropathy. Kidney Int Rep 3: 302-313, 2017.

38. Tachibana S, Iyoda M, Suzuki T, Kanazawa N, Iseri K, Wada Y, Matsumoto K and Shibata T: Serum uromodulin is associated with the severity of clinicopathological findings in ANCA-associated glomerulonephritis. PLoS One 14: e0224690, 2019.

39. Sjaarda J, Gerstein HC, Yusuf S, Treleaven D, Walsh M, Mann JF, Hess S and Paré G: Blood HER2 and uromodulin as causal nediators of CKD. J Am Soc Nephrol 29: 1326-1335, 2018.

40. Bjornstad P, Wiromrat P, Johnson RJ, Sippl R, Cherney DZ, Wong R, Rewers MJ and Snell-Bergeon JK: Serum uromodulin predicts less coronary artery calcification and diabetic kidney disease over 12 years in adults with type 1 diabetes: The CACTI Study. Diabetes Care 42: 297-302, 2019.

41. Wang L, Peng SW and Liu Q: The relationship between interleukin 6 and periodontitis Chinese Journal of Conservative Dentistry 1: 53-56, 2003 (In Chinese).

42. LaFavers KA,MacedoE, Garimella PS,Lima C, Khan S, Myslinski J, McClintick J, WitzmannFA, Winfree S, Phillips CL et al:Circulating uromodulin inhibits systemic oxidative stress by inactivating the TRPM2 channel. Sci Transl Med 11: 11, 2019.

43. Then C, Then H, Lechner A, Huth C, Meisinger C, Heier M, Peters A, Koenig W, Rathmann W, Herder C, et al: Serum uromodulin is inversely associated with the metabolic syndrome in the KORA F4 study. Endocr Connect 8: 1363-1371, 2019.

44. Wheeler E and Thomas S: Diagnosis and long-term management of uromodulin kidney disease. Cureus 11: e4270, 2019.

(c) (i) () $(9)$ This work is licensed under a Creative Commons Attribution-NonCommercial-NoDerivatives 4.0 International (CC BY-NC-ND 4.0) License. 